\title{
Photothermal Properties of Shape Memory Polymer Micro-Actuators for Treating Stroke
}

\author{
D.J. Maitland, M.F. Metzger, D. Schumann, A. Lee and \\ T.S. Wilson
}

This article was submitted to

The American Society for Laser Medicine and Surgery $21^{\text {st }}$ Annual Meeting, New Orleans, Louisiana, April 17-22, 2001

U.S. Department of Energy

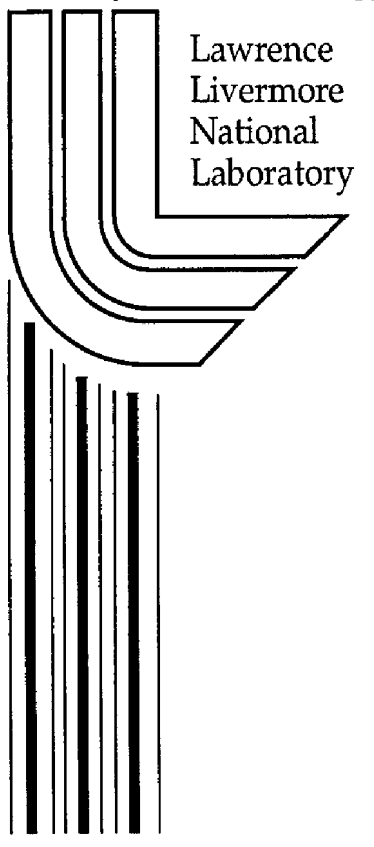

March 5, 2001 


\section{DISCLAIMER}

This document was prepared as an account of work sponsored by an agency of the United States Government. Neither the United States Government nor the University of California nor any of their employees, makes any warranty, express or implied, or assumes any legal liability or responsibility for the accuracy, completeness, or usefulness of any information, apparatus, product, or process disclosed, or represents that its use would not infringe privately owned rights. Reference herein to any specific commercial product, process, or service by trade name, trademark, manufacturer, or otherwise, does not necessarily constitute or imply its endorsement, recommendation, or favoring by the United States Government or the University of California. The views and opinions of authors expressed herein do not necessarily state or reflect those of the United States Government or the University of California, and shall not be used for advertising or product endorsement purposes.

This is a preprint of a paper intended for publication in a journal or proceedings. Since changes may be made before publication, this preprint is made available with the understanding that it will not be cited or reproduced without the permission of the author.

This report has been reproduced directly from the best available copy.

Available electronically at http://www.doc.gov/bridge

Available for a processing fee to U.S. Department of Energy

And its contractors in paper from

U.S. Department of Energy

Office of Scientific and Technical Information

P.O. Box 62

Oak Ridge, TN 37831-0062

Telephone: (865) 576-8401

Facsimile: (865) 576-5728

E-mail: reports@adonis.osti.gov

Available for the sale to the public from

U.S. Department of Commerce

National Technical Information Service

5285 Port Royal Road

Springfield, VA 22161

Telephone: (800) 553-6847

Facsimile: (703) 605-6900

E-mail: orders@ntis.fedworld.gov

Online ordering: http:/ / www.ntis.gov/ordering.htm

\section{OR}

Lawrence Livermore National Laboratory

Technical Information Department's Digital Library

http: / / www.llnl.gov/tid/Library.html 
Photothermal Properties of Shape Memory Polymer Micro-Actuators for Treating Stroke

Duncan J. Maitland, Ph.D., Melodie F. Metzger, Daniel Schumann, Abraham Lee, Ph.D., and Thomas S. Wilson, Ph.D.

Lawrence Livermore National Laboratory

Livermore, California 94550

\section{Acknowledgments}

The authors would sincerely like to thank Paul Ahre at LLNL for fabricating the SMP coil mold. This work was funded by grant \# LAB 99-18, U.S. Department of Energy, Office of Biological and Environmental Research, Medical Sciences Division.

This work was performed under the auspices of the U.S. Department of Energy by the University of California, Lawrence Livermore National Laboratory under Contract No. W-7405-Eng-48.

Address all correspondence to

Duncan J. Maitland, Ph.D.

Medical Technology Program

Lawrence Livermore National Laboratory

7000 East Avenue, Mail Stop L-174

Livermore, CA 94550

ph: $925-423-6697$

fax: 925-424-2778

email: dmaitland@llnl.gov 


\begin{abstract}
Objective: In this paper the photothermal design aspects of novel shape memory polymer (SMP) microactuators for treating stroke are presented. Materials and Methods: A total of three devices will be presented: two interventional ischemic stroke devices (coil and umbrella) and one device for releasing embolic coils (microgripper). The optical properties of SMP, methods for coupling laser light into SMP, heating distributions in the SMP devices and the impact of operating the thermally activated material in a blood vessel are presented. Results: Actuating the devices requires device temperatures in the range of $65^{\circ} \mathrm{C}-85^{\circ} \mathrm{C}$. Attaining these temperatures under flow conditions requires critical engineering of the SMP optical properties, optical coupling into the SMP, and device geometries. Conclusion: Laser-activated SMP devices are a unique combination of laser-tissue and biomaterial technologies. Successful deployment of the microactuator requires well-engineered coupling of the light from the diffusing fiber through the blood into the SMP.
\end{abstract}




\section{Key Words}

Diode laser, hemorrhagic stroke, ischemic stroke, biomaterial 


\section{Introduction}

In this study we report on the photothermal design issues for laser-activated shape memory polymer (SMP) devices that are under development for endovascular treatment of ischemic stroke and cerebrovascular aneurysms. Stroke is a major cause of death $(155,000 /$ year) and is the primary cause of long-term disability in the United States $[1,2]$. Approximately 730,000 strokes occur annually in the United States, accounting for costs of over $\$ 40$ billion/year for treatment and rehabilitation [3]. Large vessel ischemic strokes, typically caused by the formation or lodging of a thrombus (blood clot) in the arterial network supplying the brain, account for approximately $60 \%$ of strokes $(\sim 400,000 / \mathrm{yr})$; the remainder are hemorrhagic strokes $(20 \%)$ and small vessel ischemic strokes $(20 \%)$ [1]. Of the hemorrhagic strokes, approximately $15,000 / y r$ are the result from a ruptured aneurysm [4]. The probability that a patient with an unruptured intracranial aneurysm (UIA) will rupture (stroke) is a current clinical research topic and is known to vary with aneurysm size and location. In the largest study to date, rupture rates were reported at a rate of $0.05 \% / \mathrm{yr}$ in patients with aneurysms $<10 \mathrm{~mm}$ in diameter and $1 \%$ in patients with aneurysms $\geq 10 \mathrm{~mm}$ in diameter [5]. Hence, the number of recommended treatable patients with UIA ( $\geq 10 \mathrm{~mm}$ in diameter, [4]) in the US is as large as $1,000,000 / y r$.

Currently, the only approved therapy for treatment of acute ischemic stroke is intravenous recombinant tissue plasminogen activator (tPA). While stroke patients who receive i.v. tPA are more likely to have better outcomes than those who do not, their improvement is highly dependent on the initiation of treatment within three hours of the onset of symptoms, with no improvement of outcome and an increased risk of intracranial hemorrhage if the medication is begun outside this time window [6]. After this three hour window, tPA is ineffective at lysing the clot. With this rigid temporal limitation, and with the concern over intracranial hemorrhage, only $2-3 \%$ of people with acute stroke are currently being treated by this means [7]. Since, under current protocols, the efficacy of tPA limits the window of opportunity for revascularization to three hours of symptom onset, the issue becomes the duration of the time window during which the patient would benefit. Early clinical and animal studies have shown that reperfusion up to 9 hours after stroke onset results in full neurological recovery [8]. Thus, a difference of up to 6 hours exists between the efficacy of the current therapy and timing of future, perhaps mechanical, therapies. Two recent reports $[9,10]$ of mechanical removal of thrombus which was resistant to pharmacologic lysis, with subsequent improved patient outcome, highlights the principle and the necessity behind the development and testing of devices specifically designed for this purpose.

A promising approach for treating ischemic stoke is the mechanical removal of thrombi using a novel microactuator device as demonstrated in Figure 1. The device consists of an injection-molded shape memory polymer microactuator that is delivered through a catheter distal to the thrombolic occlusion. The microactuator is mounted on a diffusing optical fiber and delivered in its straight form through a catheter (e.g., Target Therapeutics Tracker $\left.18,0.018^{\prime \prime}(450 \mu \mathrm{m}) \mathrm{ID}\right)$ distal to the occlusion, where it is deployed 
via optical heating into its coil shape. Once the device is deployed, both the microactuator and the thrombus are removed from the vessel, restoring blood flow.

The current FDA-approved endovascular therapy for treating neurovascular aneurysms that may lead to a hemorrhagic stroke is the Guglielmi detachable coil (GDC) [11]. In the GDC system, UIAs are packed with embolic coils that cause the blood in the aneurysm to clot and eventually heal over such that the threat of rupture is eliminated. The coils are released from the delivery wire by means of electrolytic dissolution of a metallic bridge that connects the platinum coil to the stainless steel wire $(1-5 \mathrm{~min} / \mathrm{coil})$. Since a single aneurysm may require as many as 20 coils, the downside of this system is the time required to release the total number of coils.

The same laser-activated SMP technology that is used in developing the interventional ischemic stroke device can be used in designing a fast actuating embolic coil release system (see Figure 2). This system has been patented and demonstrated to release the coil in a second or less [12].

The ischemic and hemorrhagic stroke therapies are enabled by polymers that display shape memory behavior, i.e., they can be formed into a primary shape, subsequently deformed into a stable secondary shape, and then controllably actuated to recover their primary shape. Such behavior has been reported in a wide variety of polymers including polyisoprene [13] and segmented polyurethanes [14]. Although there is wide chemical variation in these materials, they can be grouped into categories with high physical similarity based on the method of actuation, which can be achieved thermally, through photo induced reaction, or by changing the chemical environment [15]. For example, thermal SMPs are typically described as having a hard, or fixing phase and a soft, or reversible phase. The fixing phase consists of a dispersed glassy phase, crystallinity, or chemical crosslinks that provide the structure necessary for memorization of the primary shape. The reversible phase makes up the material matrix; it can be either amorphous or semicrystalline, and stores most of the actual deformation imposed on the material during formation of the secondary shape. The microactuator-based devices described in this work are composed of a thermal SMP.

The physical mechanism for the operation of an SMP microactuator is different from that of the more commonly used shape memory alloys (SMAs). This difference can be explained with reference to their thermomechanical behavior (Figure 3). In SMAs, the shape memory effect is related to the local cooperative reordering of lattice atoms that occurs when a deformed SMA is heated from the martensitic phase to the austenitic phase (above $A_{s}$ in Figure 3) [15]. In thermal SMPs, the primary shape is formed at a temperature above the highest glass $\left(T_{g}\right)$ or crystalline $\left(T_{m}\right)$ transition and then the polymer is either cooled (thermoplastics) or crosslinked (thermosets) in order to fix the shape. Next, the secondary shape is obtained by deforming the material at a temperature above the soft phase glass transition temperature $\left(T_{g s}\right)$ or soft phase crystalline melting temperature $\left(T_{\mathrm{ms}}\right)$ and stabilized by cooling below the same soft phase transition. This deformation is stored elastically as macromolecular chain orientation; hence, there is an entropic potential for shape recovery. However, by cooling below the soft phase $\mathrm{T}_{\mathrm{gs}}$ or 
$\mathrm{T}_{\mathrm{ms}}$, the soft phase modulus increases by orders of magnitude, effectively retarding this recovery. Finally, recovery of the primary shape is achieved by heating the material once again above the soft phase $\mathrm{T}_{\mathrm{gs}}$ or $\mathrm{T}_{\mathrm{ms}}$.

The first commercial application of the polymer shape memory effect involved the use of radiation crosslinked polyethylene for heat shrink film and tubing [16]. Researchers at Mitsubishi later developed a series of segmented polyurethanes for use in expandable foam for packaging $[14,17]$, and adopted the term "shape memory polymer" to describe those specific materials as is done here. Since the soft segment glass transition of those materials could be controlled over the temperature range from $30^{\circ} \mathrm{C}$ to above $70^{\circ} \mathrm{C}$ [18], and since polyurethanes are generally biocompatible, they are particularly well suited for medical applications involving internal short-term use [19]. Since their introduction, several medical applications have been documented. These include implant devices [20], catheters [21], microactuators [22], and optical heating of shape memory devices [23].

In this paper the engineering issues for using lasers to heat and subsequently actuate SMP devices are presented. A total of three devices will be presented: two interventional ischemic stroke devices (coil and umbrella) and one device for releasing embolic coils (microgripper). The optical properties of SMP, methods for coupling laser light into SMP, heating distributions in the SMP devices and the impact of operating the thermally activated material in a blood vessel (with and without flow) are presented. 


\section{Materials and Methods}

\section{Optical Properties}

The refractive index and optical absorption curve were measured for the SMP (thermoset polyurethane MP $5510-\mathrm{T}_{\mathrm{gs}}=55^{\circ} \mathrm{C}$, Memry Corp., distributor for Mitsubishi Heavy Industries, Ltd.). Two designs for an ischemic stroke device were fabricated injection molding. Samples for optical testing were produced using injection molding in a similar manner to the ischemic stroke devices except a rectangular mold was used with dimensions $3 "$ " $0.50^{\prime \prime} \times 0.125^{\prime \prime}$. The embolic coil microgripper was extruded using a thermoplastic SMP $\left(\mathrm{T}_{\mathrm{gs}}=55^{\circ} \mathrm{C}\right)$.

The absorption coefficient was measured on the 0.125 " thick sample over the wavelength range of 400-900 $\mathrm{nm}$ (Perkin Elmer, Lambda). Several samples were doped with a green dye (Ryvec-518) at concentrations of $0.06 \%-0.2 \%$ by weight. The refractive index of the $0.06 \%$ sample was also measured at $589 \mathrm{~nm}$ and corrected to $20^{\circ} \mathrm{C}$ (Reichert ABBE Mark II Digital Refractometer).

\section{Laser-SMP Optical Coupling}

The optical system for used in heating the SMP devices is shown in Figure 4. The laser used is a fiber pigtailed $1.5 \mathrm{~W}$ diode laser (OptoPower Corporation) operating at $810 \mathrm{~nm}$ at $0.1-1.5$ watts for $0.1-2.0$ seconds. The $2 \times 2$ (90\%-10\%, Amphenol) fiber coupler and two photodetectors (Melles Griot, silicon photodiode) enable both the laser power to be monitored and, if applicable, a feedback signal resulting from the status of the actuation to be monitored. Throughout the optical system, $100 \mu \mathrm{m}$ core step index fibers are used. In order to minimize the diameter of the fibers used in the Pusher (delivery) section, a polyimide buffered fiber is used (Polymicro, 100/120/140 $\mu \mathrm{m}$ low $\mathrm{OH}$ silica fiber). The prototype system uses a laptop computer running LabView and a data acquisition card (National Instruments) to control the laser.

Depending on the device geometry, efficient coupling of the laser light into the SMP may require some modifications to the fiber-SMP interface. In the case of the microgripper depicted in Figure 2, the end of the fiber was modified over, approximately, the last 500 $\mu \mathrm{m}$ to be radially diffusing. The protocol used for creating a $100 \mu \mathrm{m}$ diameter diffusing fiber was to first etch the cladding off the fiber core using $100 \%$ hydrofluoric acid for 15 minutes. The buffer was previously removed using a cylindrical heating element that burns the buffer off (Bahr and Associates). The acid-etched fiber is dip coated with UVcured optical adhesive (Norland Products) and cured. The hardened adhesive coating has a refractive index larger than the fiber core such that light couples efficiently into the adhesive. The final step in making a cylindrically diffusing tip is mechanically abrading the coating surface ( $5 \mu \mathrm{m}$ particle size). The umbrella device also used a cylindrically diffusing fiber section prepared in the same manner. The coil device currently uses straight fiber-SMP coupling but this device is the least mature and still under development. 


\section{Thermal Flow Measurements}

A thermal camera (Inframetrics, $0.01{ }^{\circ} \mathrm{C}$ resolution, $10 \mu \mathrm{m}$ spatial resolution, $30 \mathrm{~Hz}$ video capture rate) was used to image the temperatures that result in the optical heating of the SMP devices. The experiments were conducted with the microgripper in air or partially submerged in a controlled flow channel $(4 \times 4 \mathrm{~mm})$. The microgrippers used in the flow studies had one-half to two-thirds of their surface area submerged in a flow stream. The microgrippers could not be completely submerged because the thermal camera does not work through water. The images were used to determine the axial and radial uniformity and magnitude of heating with a $37^{\circ} \mathrm{C}$ water flowing at rates of $0-100$ $\mathrm{ml} / \mathrm{min}$ in a $4 \mathrm{~mm}$ square channel.

A second set of experiments validated the thermal camera temperature measurements for completely submerged devices. A number of coil drop tests were performed for various flows $(0-100 \mathrm{ml} / \mathrm{min}$ in a $3 \mathrm{~mm}$ inner diameter polyvinyl chloride tube). The same laser power and pulse durations were used to determine if the SMP would actuate as predicted by the temperatures in the infrared images. In general, laser powers needed to be increase by $20 \%$ over those predicted in the infrared image measurements to actuate the devices. 


\section{Results}

\section{Device Operation}

The most mature device is the microgripper used in releasing embolic coils. This device is shown in Figure 5. The device has been licensed to industry. The interventional devices for treating large vessel ischemic stroke are currently under development. The operation of these devices is demonstrated in Figure 6. The umbrella has been functionally operated in a saline-filled polyvinyl chloride $3 \mathrm{~mm}$ inner diameter tube with a $2 \mathrm{~cm}$ long blood clot. The collapsed umbrella was pushed past the clot, activated with a laser pulse of $0.25 \mathrm{~W}$ for 5 seconds and drawn proximally to successfully capture the clot. Both the umbrella and coil have been demonstrated in bench-top functional tests to hold blood clots in $1.5 \mathrm{~mm}$ inner diameter polyvinyl chloride tubing for pressures of $1078 \pm 249 \mathrm{mmHg}$. These pressures are an order of magnitude greater than physiological Cerebrovascular pressures.

\section{Optical Properties}

The refractive index of the $0.06 \%$ wt. doped MP 5510 was $1.5799 \pm 0.0002$ at $589 \mathrm{~nm}$. The absorption coefficient for the same SMP is shown in Figure 7. The absorption coefficient at the diode laser wavelength of $810 \mathrm{~nm}$ is $3.65 \mathrm{~cm}^{-1}$ that equates to a mean free path of $2.7 \mathrm{~mm}$. The absorption coefficient scales linearly with concentration through $0.2 \%$ wt. doping (largest measured).

\section{Thermal and Flow Measurements}

Figure 8 shows an example of an image captured with the thermal camera. Spatial and temporal thermal profiles were extracted from similar images and used to optimize a large parameter space of device design/geometries, laser powers and flow rates. Similar studies are currently underway for the ischemic stroke devices. Figure 9 shows the temperature gradients due to flow and different absorption coefficients (inset figure). A variety of optical coupling schemes were tested in this way with the diffusing fiber tip resulting as the optimum design. Figure 9 shows an alternative design with a gap between a non-diffusing fiber and the coil. Optimum dye concentrations were determined to be between $0.05 \%-0.1 \%$ wt., depending on the coil-SMP overlap. Figure 10 shows examples of data collected from the flow studies on the partially submerged microgrippers. The general conclusion of these studies was that no single laser power was appropriate for operating the microgripper under all required flow conditions $(0-100$ $\mathrm{ml} / \mathrm{min})$. 


\section{Discussion}

We believe that shape memory polymers will have a significant impact on medical devices. SMP has unique properties that enable the manufacture of devices not possible with current materials. For example, SMPs have several advantages over SMAs including cost, higher recoverable strain levels ( $300 \%$ versus $10 \%$ ), ease of manufacturing, better flexibility in navigating tortuous paths, and great versatility in fabricating extremely small, highly complex actuators. The possible disadvantages of SMP are unknown material properties and lower actuation forces (relative to SMAs). Potential applications of SMP include stents, stent release mechanisms, embolic coil release mechanisms, thrombus extraction devices, and many others.

Relative to the SMP devices presented here, several common photothermal design criteria can be identified:

1. The endovascular devices cannot cause collateral thermal damage to the blood vessels,

2. The devices must be heated as uniformly as possible with the default requirement that the minimum SMP temperature be sufficient for actuation $\left(\sim 60^{\circ} \mathrm{C}\right)$ and the maximum SMP temperature be lower than the SMP melt or damage threshold $\left(100-150{ }^{\circ} \mathrm{C}\right)$,

3. The minimum and maximum temperatures discussed in criterion 2 must hold under all flow conditions possible in the given vascular anatomy.

The first, safety-driven photothermal design criterion is complicated. Although no know written FDA requirement exists, the very common verbal stipulation is that no collateral tissue may be heated by more than that of a high-grade fever or, approximately, $5^{\circ} \mathrm{C}$ above normal body temperature. This requirement is not practically imposed on devices though. The data accepted by the FDA is histologic evaluation of animal model vascular tissue exposed to the device under a series of power level, operating duration and flow conditions. If the vascular tissue sections show no thermal damage then the device is assumed safe for human use (relative to collateral thermal damage issues only). The difference between the stated $5{ }^{\circ} \mathrm{C}$ criterion and the gold standard test is twofold kinetics and the cooling capacity of fluids.

Kinetics is the key factor in determining if a given heated object will cause thermal damage in a vessel. In short, it is the time-temperature history and not just the temperature that matters. That is, high temperatures can only be applied for short durations before damage results and low temperatures for much longer times. The kinetic rate constant, $\mathbf{k}$, quantifies this time at a given temperature. In this case, $\mathbf{k}$, describes the rate that tissue changes from native to denatured (thermally damaged) [24]. Thus $\mathrm{k}^{-1}$ is the characteristic time for thermal damage to occur. An applied example of this is to determine the time required to thermally damage an important structural constituent of arteries, collagen, at 50,60 , and $70^{\circ} \mathrm{C}$. Using the thermodynamic parameters found for collagen using birefringence measurements $(\Delta \mathrm{H}=368 \mathrm{~kJ} / \mathrm{mol}, \Delta \mathrm{S}=0.824 \mathrm{~kJ} / \mathrm{mol}-\mathrm{K},[25])$, the inverse rate constants are calculated to be 4485,71 , and 1 second for 50,60 , and 70 ${ }^{\circ} \mathrm{C}$, respectively. Thus a $60^{\circ} \mathrm{C}$ temperature could be tolerated for some fraction of 71 
$\mathrm{J} /\left(\mathrm{g}^{\circ} \mathrm{C}\right.$ ) (approximately 4 for water and 3.3 for blood) and $\mathrm{V}$ is the total volume in $\mathrm{cm}^{3}$. Using the microgripper as an example, assume that it is operating in a $4 \mathrm{~mm}$ inner diameter artery under no flow conditions. Further assume as a worse case estimate that only the blood along a $5 \mathrm{~mm}$ length of the device is available for cooling. Under these assumptions, the temperature rise is estimated as $5 \mathrm{Pt}$. The laser powers used for the microgripper are approximately $0.2 \mathrm{~W}$ at the SMP for 1 second. Thus, $\Delta \mathrm{T} \sim 1^{\circ} \mathrm{C}$ and no damage is expected to occur even though some area of the SMP would be at temperatures around $85-90^{\circ} \mathrm{C}$. This example was well substantiated by animal model histology. Similar reasoning is currently being used in the development of the SMP ischemic stroke devices (see Figure 6).

A second, more extreme example from another endovascular device developed by our group, a vacuum tube, $\mathrm{x}$-ray producing catheter was simulated by a hollow aluminum cylindrical $1 \mathrm{~mm}$ diameter by $3 \mathrm{~mm}$ long beam dump that was heated by internally absorbing $1 \mathrm{~W}$ of laser energy. The internal temperatures of the device reached over 120 ${ }^{\circ} \mathrm{C}$. In this case the device was engineered such that it would always be centered in the vessel and $1 \mathrm{ml} / \mathrm{min}$ of forced saline flow was required. The maximum steady state temperature rise in the blood or at the vessel wall ( $4 \mathrm{~mm}$ inner diameter) was measured to be $2{ }^{\circ} \mathrm{C}$ above ambient. Since the potential for catastrophic damage existed in the x-ray device, an additional engineering safety feature was the inclusion of an on board temperature sensor that would turn off the device power if rapid heating was detected. This device must operate for minutes at a time. Using the same empirical model as the preceding paragraph, $\Delta \mathrm{T}\left({ }^{\circ} \mathrm{C}\right)=\mathrm{P} /(\mathrm{Cp} \mathrm{f})$, where $\mathrm{P}$ is the steady state power and $\mathrm{f}$ is now flow rate in $\mathrm{ml} / \mathrm{s}$. For the above conditions, $\Delta \mathrm{T}=4^{\circ} \mathrm{C}$. We believe that the measured temperature rise is less than the rule of thumb calculation because there was some flow in the vessel besides the forced saline from a catheter and conductive cooling will also come into play for minute timescales.

An important note is that the convective fluid cooling rule of thumb does not apply to direct laser heating of tissue or if a large area of a heated device is in contact with the artery wall.

The second (uniform temperature distribution) design criterion influences the engineering of the SMP absorption coefficient used in various devices. In the case of the microgripper, dye concentrations of $0.06 \%$ resulted in a mean free path (mfp) of $2.7 \mathrm{~mm}$, which was approximately twice the length of the SMP overlap on the coil. Theoretically, this would result in fiber-coil temperature increases approximately 1.4 times the temperature increase observed at the distal tip. A more uniform temperature profile could be obtained by lowering the dye concentration (absorption coefficient) but this would also result in a lower energy deposited per unit volume. The deposited energy is equal to the intensity, which is a function of time and geometry, multiplied by the absorption coefficient. In the case of the microgripper, financial constraints governed by a lower power, lower cost laser such that the option to flatten the temperature profile was limited. In general, if the laser power is available, lower absorption coefficients are better for uniform temperature distributions. The current design for the ischemic stroke SMP coil, which has an elongated length of $4 \mathrm{~mm}$ and diameter of $0.2 \mathrm{~mm}$, is using dye 
concentrations $0.01 \%\left(\mu_{\mathrm{a}}=0.6 \mathrm{~cm}^{-1}\right)-0.02 \%\left(\mu_{\mathrm{a}}=1.2 \mathrm{~cm}^{-1}\right)$. Since the umbrella device is irradiated from the side and will be in a blood environment $\left(\mu_{\mathrm{a}}=4.7 \mathrm{~cm}^{-1}, 2.1 \mathrm{~mm} \mathrm{mfp}\right.$, [26]), its absorption coefficient is $12.2 \mathrm{~cm}^{-1}$ ( $\mathrm{mfp}=0.8 \mathrm{~mm}$, thickness $0.2 \mathrm{~mm}$ ).

Note that the wave-guide characteristics of the SMP $(n=1.5)$ in a blood $(n=1.4)$ or water $(n=1.3)$ environment is a useful engineering tool in designing these devices. Other heating methods (e.g. resistive and radio frequency heating) do not take advantage of the selectivity enabled by the wave-guide effect. The net outcome is to evenly distribute light within the SMP. As long as sharp corners and bends are avoided, the light will propagate in the SMP. This factor was not fully considered in the first prototype of the ischemic coil device shown in Figure 6. The square cross section causes a large amount of leakage such that laser activation is possible but not practical. A redesigned mold with a round cross section is currently being fabricated.

The third design criterion is that all of these devices work under all relevant flow conditions. The data for the microgripper in Figure 10 show that this can be a difficult constraint. A neurovascular aneurysm off the middle cerebral artery could have flow rates as large as $100 \mathrm{ml} / \mathrm{min}$. If the embolic coil therapy is successful, then this flow will be reduced as coils are deposited and will be near or at $0 \mathrm{ml} / \mathrm{min}$ at the end of the procedure. We could not find any single laser power that successfully actuated the gripper release for this flow range. Referring to Figure 10, there is no single laser power, pulse duration that would raise the distal SMP above $65^{\circ} \mathrm{C}$ in the $95 \mathrm{ml} / \mathrm{min}$ flow condition and not overheat the SMP in the $18 \mathrm{ml} / \mathrm{min}$ case. The design issue was solved by physically modifying the device so that the SMP always was exposed to $0-10 \mathrm{ml} / \mathrm{min}$ flow conditions independent of the vascular flow rate. This engineering fix also resulted in lower laser powers. Experiments are currently underway to determine the flow requirements for the ischemic devices. 


\section{References}

1. Broderick JP, Lu M, Kothari R, Levine SR, Lyden PD, Haley EC, Brott TG, Grotta J, Tilley BC, Marler JR, Frankel M. The greater Cincinnati/Northern Kentucky stroke study: Preliminary first-ever and total incidence rates of stroke among blacks. Stroke 1998, 29:415-421.

2. National Stroke Association, Brain Attack Statistics http://www.stroke.org/brain stat.cfm

3. Gorelick PB, Sacco RL, Smith DB, Alberts M, Mustone-Alexander L, Rader D, Ross JL, Raps E, Ozer MN, Brass LM, Malone ME, Goldberg S, Booss J, Hanley DF, Toole JF, Greengold NL, Rhew DC. Prevention of first stroke: A review of guidelines and a multidisciplinary consensus statement from the National Stroke Association. JAMA 1999, 281:1112-1120.

4. Benderson JB, Awad IA, Wiebers DO, Piepgras D, Haley EC, Brott T, Hademenos G, Chyatte D, Rosenwasser R, Caroselli C. American Heart Association Scientific Statement. Recommendations for the Management of Patients With Unruptured Intracranial Aneurysms. Stroke. 2000; 31:2742-2750.

5. ISUIA Investigators. Unruptured intracranial aneurysms: risks of rupture and risks of surgical intervention. N Engl J Med. 1998; 339:1725-1733.

6. The National Institutes of Neurologic Disorders and Stroke (NINDS) rt-PA Stroke Study Group. Tissue plasminogen activator for acute ischemic stroke NEJM 1995, 333:1581-1587.

7. Katzan IL, Furlan AJ, Lloyd LE, Frank JI, Harper DL, Hinchey JA, Hammel JP, $\mathrm{Qu} A$, Sila CA. Use of tissue-type plasminogen activator for acute ischemic stroke: The Cleveland area experience. JAMA 2000, 283:1151-1158.

8. Connors JJ and Wojak JC. Strategic Considerations Concerning Emergency Stroke Treatment. In: Connors JJ and Wojak JC, eds. Interventional Neuroradiology. Philadelphia, PA. 1999 pp. 650-691.

9. Vesely TM, Williams D, Weiss M, Hicks M, Stainken B, Matalon T, and Dolmatch B. Comparison of the angiojet rheolytic catheter to surgical thrombectomy for the treatment of thrombosed hemodialysis grafts. Peripheral AngioJet Clinical Trial. J Vasc Interv Radiol 1999, 10(9):1195-1205.

10. Opatowsky MJ, Morris PP, Regan JD, Mewborne JD, and Wilson JA. Rapid thrombectomy of superior sagittal sinus and transverse sinus thrombosis with a rheolytic catheter device. AJNR Am J Neuroradiol 1999, 20(3):414-417.

11. Connors JJ and Wojak JC. Intracranial Aneurysms: General Considerations. In: Connors JJ and Wojak JC, eds. Interventional Neuroradiology. Philadelphia, PA. 1999 pp. 276-294.

12. Maitland DJ, Lee AP, Schumann DL, and Da Silva L, Shape Memory Polymer Gripper Release System with Sensing of Target Release, US Patent 6,102,917, 1998. 
13. W. Wang and L. Zhang.Recovery as a Measure of Oriented Crystalline Structure in Poly(ether ester)s Based on Poly(ethylene oxide) and Poly(ethylene terephthalate) used as Shape Memory Polymers. J Pol Sci B: Pol Phy. 1999, 37 : 101.

14. Hayashi S and Shirai Y. Mitsubishi Technical Bulletin No. 184, December 1988.

15. Otsuka K and Wayman CM. Shape Memory Materials. New York: Cambridge University Press 1998.

16. Ota S. Current Status of Irradiated Heat-Shrinkable Tubing in Japan. Radiat Phys Chem 1981, 18: 81.

17. Hayashi S and Fujimura H. Shape Memory Polymer Foam, U.S. Patent No. 5049591, 1991.

18. Takahashi T, Hayashi N, Hayashi S. Structure and Properties of Shape-Memory Polyurethane Block Copolymers. J Appl Pol Sci 1996, 60:1061.

19. Ratner BD and Hoffman AS. Thin Films Grafts and Coatings. In: Ratner BD, Hoffman AS, Schoen FJ, Lemons JE, eds. Introduction to Materials in Medicine. New York: Academic Press 1996.

20. Kusy RP, Whitley JQ. Thermal Characterization of Shape-Memory Polymer Blends for Biomedical Implantations. Thermochimica Acta 1994, 243: 253.

21. LaFontaine D, Guide Catheter with Shape Memory Retention, US Patent No. $5662621,1996$.

22. Benett WJ, Krulevitch PA,Lee AP, Northrup MA,Folta JA. Fabrication Method for Miniature Plastic Gripper, U.S. Patent No. 5783130, 1998.

23. Fitch JP,Matthews DL,Hagans KG,Lee AP,Krulevitch PA,Benett WJ,Clough R,Da Silva L,Celliers PM. Optical Fibers for Simultaneous Power, Communications and Control in Medical Devices, U.S. Patent No. 5722989, 1998.

24. Pearce J, Thompson S. Rate Process Analysis of Thermal Damage. In: Welch AJ and van Gemert MJC. eds. Optical-Thermal Response of Laser-Irradiated Tissue. New York: Plenum 1995: 561-603.

25. Maitland DJ, Walsh JT, Jr. Quantitative measurements of linear birefringence during the heating of native collagen. Lasers Surg Med 1997; 20: 310-318.

26. Prahl S, http://www.omlc.ogi.edu/spectra/hemoglobin/index.html 


\section{Figure Captions}

Fig. 1. Schematic representation of SMP microactuator used in treating ischemic stroke. (a) The guide catheter is pushed through or around the blockage. (b) The SMP device is pushed out of the guide catheter and actuated. The SMP device must have a small enough diameter to pass through an appropriate neurovascular guide catheter. Current design goals have set this diameter to be $0.012^{\prime \prime}(300 \mu \mathrm{m})$ or less. Two appropriate devices, nominally named a coil and an umbrella, are described in this paper. (c) The catheter, expanded device (coil depicted in this schematic), and clot are pulled in unison proximally to relieve the ischemia.

Fig. 2. Schematic representation of an embolic coil release microgripper. Figure 2a shows the delivery device with the coil loaded and ready for deployment. Figure $2 \mathrm{~b}$ shows the delivery device after the SMP has been heated above its transition temperature. The SMP around the coil has mechanically relaxed (expanded) to its extruded diameter. The SMP remains in its expanded state after the laser-coupled thermal energy is turned off and the SMP cools below its transition temperature. Note that the SMP around the optical fiber has been permanently attached with an adhesive.

Fig. 3. General thermomechanical behavior of shape memory alloy (SMA) film and of a shape memory polymer (SMP) shown in the temperature range of their respective shape memory effects (plotted on a semilog scale). The SMA shows a hysteresis in the physical transformation between the austenite (A) and martensite (M) phases(s), with subscripts (s) indicating the start and (f) the finish of the transition. Shape recovery is complete when the SMA is heated above $A_{f}$. In the lower curve a major change in modulus is seen at the soft phase glass transition ( $T_{g s}$ ), where the SMP goes from being a hard to a rubbery consistency. Heating the SMP above $T_{\mathrm{gs}}$ is necessary for shape recovery. The SMP shown would be useful for medical device applications in which actuation occurs within the body. The minimum temperature required for actuating the SMP material depicted in the generic curve is approximately $\mathrm{T}_{\mathrm{gs}}=55^{\circ} \mathrm{C}$, which is typical of the SMP devices used in medicine.

Fig. 4. A schematic overview of the optical system for heating SMP devices. Laser light is transmitted through a multimode optical fiber, a fiber coupler, an extension fiber that enters the sterile surgical field, and a fiber pusher with the SMP actuator at its distal tip. A small amount of laser light is reflected from the fiber-SMP interface back through the coupler into the photodetector. Source fluctuations may be monitored by the source photodetector. As the laser light heats the SMP in the distal tip of the catheter, the umbrella deploys. As an optional design feature, detection of the actuation can be fed back to the operator (or computer). The SMP movement causes the reflected signal to decrease. The changes in the reflected signal can be used to control the driving current of the laser or to alert an operator of the status of the actuator (e.g., open or closed).

Fig. 5. Photograph of embolic coil microgripper with self-contained driving electronics. All components depicted in the Control Unit box in Figure 4 are included in the electrooptic unit that was used in animal trials. The Control Unit features a LED bar graph at 
the top that indicates the status of the microgripper (embolic coil attached or released). The two detach buttons must be depressed simultaneously to avoid accidental detachments. A non-clinical coil is shown after passing the delivery (pusher) fiber optic through a Target Therapeutics Tracker 18 (0.018" inner diameter).

Fig. 6. Operational demonstration of the umbrella and coil microactuators. The maximum diameter of the deployed (opened) umbrella is $1 \mathrm{~mm}$ and the coil is $1.4 \mathrm{~mm}$. Heated air at $65^{\circ} \mathrm{C}$ was used to actuate the microactuators in these pictures. Both devices have been actuated with laser-activation in low flow rate room temperature water. Functional tests of the coil device have shown that porcine blood clots have been successfully held against pressures of $1078 \pm 249 \mathrm{mmHg}$ in a $1.5 \mathrm{~mm}$ inner diameter flexible, transparent polyvinyl chloride tube. This pressure are on the order of ten times average physiological pressures in the cerbrovaculature.

Fig. 7. Absorption coefficient for 0.06\% wt. doped thermoset MP 5510. Absorption coefficients were measured for both thermoset and thermoplastic SMPs with dye doping concentrations up to $0.2 \% \mathrm{wt}$. No significant differences in the absorption coefficient between the SMP types were noted. The absorption coefficient scales linearly with dye concentration through the maximum concentration tested.

Fig. 8. Example of the images obtained in measuring the temperature distributions in microgripper actuators (in air). The diffusing optical fiber coincides with the bright (hottest) section of the image near the top. The temperature indicated on the left scale $\left(32.8^{\circ} \mathrm{C}\right.$ ) is located at the cross hairs in the image (distal edge of SMP). This specific SMP microgripper is approximately $200 \mu \mathrm{m}$ in diameter and overlaps the coil by $550 \mu \mathrm{m}$ in the image. Overlap lengths between 200-2000 $\mu \mathrm{m}$ were tested with the thermal distributions compared to the static failure loads that the gripper could hold $(0.33 \mathrm{lb}$ was a minimum design requirement).

Fig. 9. Temperature distribution in partially submerged microgripper. The top schematic diagram shows an air gap between the fiber and the coil with identifying points (A-D). The temperature distribution shown is for a device partially submerged in $37^{\circ} \mathrm{C}, 5$ $\mathrm{ml} / \mathrm{min}$ water through a $4 \times 4 \mathrm{~mm}$ channel. The laser power used in this example was 98 $\mathrm{mW}$. The SMP coil overlap was approximately $200 \mu \mathrm{m}$ and the dye concentration was $0.2 \%$. The temperature drop from the points $\mathrm{B}$ to $\mathrm{A}$ was greater than $5{ }^{\circ} \mathrm{C}$ due to both the flow and the dye concentration. The inset figure shows the influence of dye concentrations on the temperature gradient of a $2000 \mu \mathrm{m}$ overlap SMP microgripper in air. Both the $0.1 \%$ and $0.2 \%$ concentrations use the same laser power $(65 \mathrm{~mW})$ and the lower concentration has a smaller temperature gradient but low temperatures due to less laser light absorbed. Note that the temperatures in the inset figure are the relative to room temperature.

Fig. 10. Peak temperature in distal end of the SMP microgripper for 18 and $95 \mathrm{ml} / \mathrm{min}$ flow rates in partially submerged tests. The lines are linear fits to the data. The same laser powers (measured at the fiber end with an integrating sphere) are shown for both flow cases. The general conclusion of these studies was that no single laser power was 
appropriate for operating the microgripper under all required flow conditions (0-100 $\mathrm{ml} / \mathrm{min}$ ). Note that for a given flow rate, lower and higher laser powers result in fairly linear temperature-time behavior. For all cases tested ( 5 flow rates between 0-100 $\mathrm{ml} / \mathrm{min}$ ), non-linear temperature-time data resulted. The source on the nonlinearity is unknown but suspected to occur when the energy output of the SMP was near the maximum energy input (energy sink) capacity of the flowing fluid. The $18 \mathrm{ml} / \mathrm{min}$ flow condition required that the laser pulse duration be smaller due to excessive heating for the higher laser powers. 

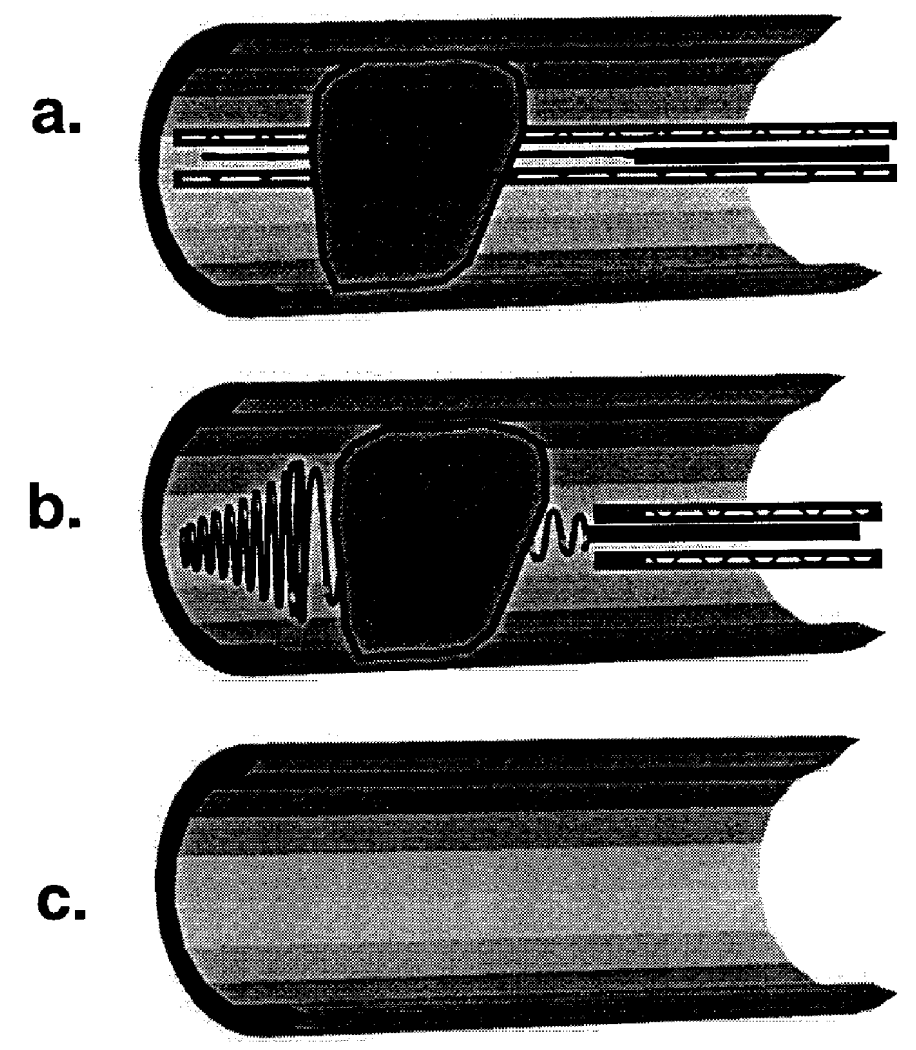

$F: 8$ 

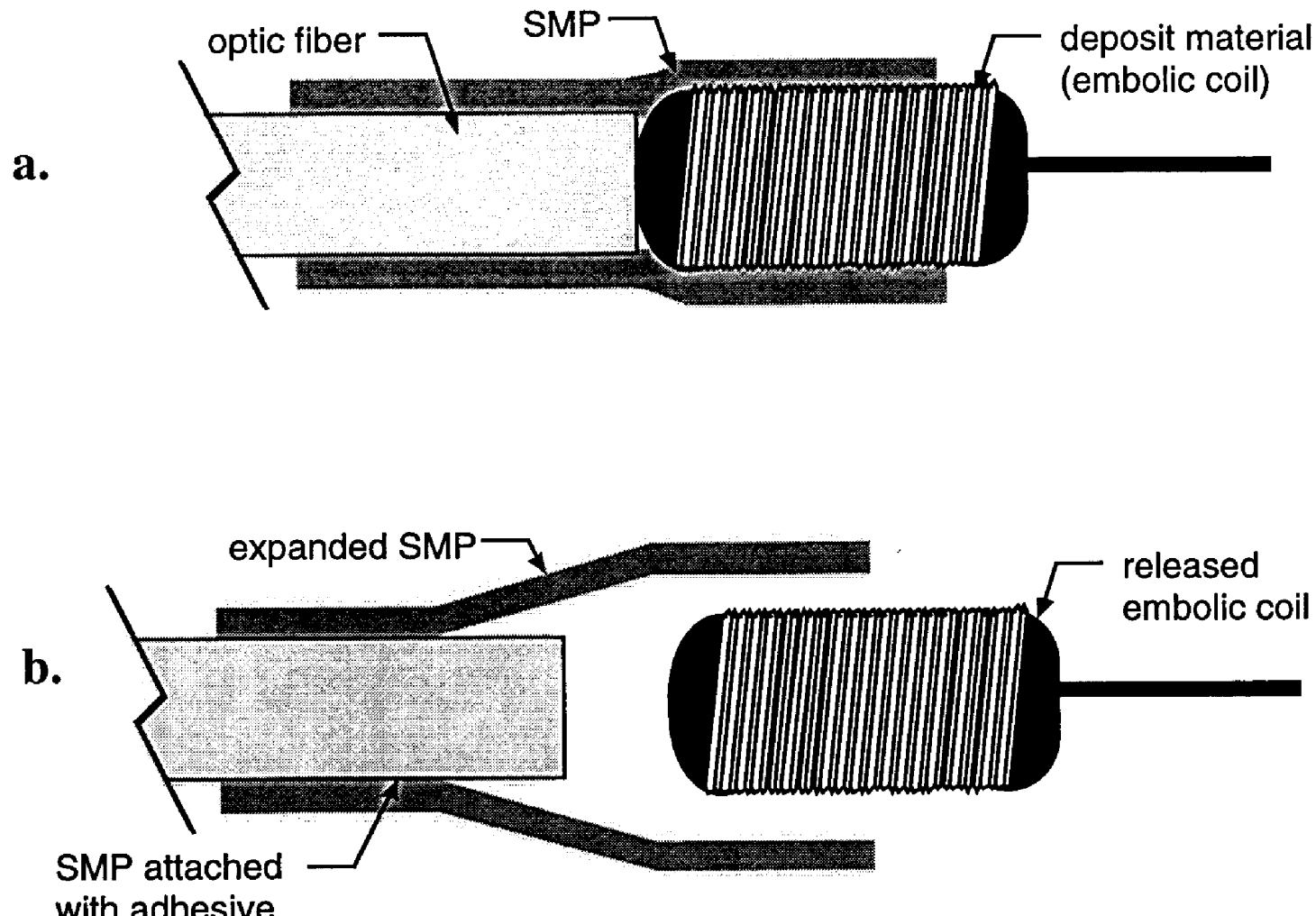
with adhesive 


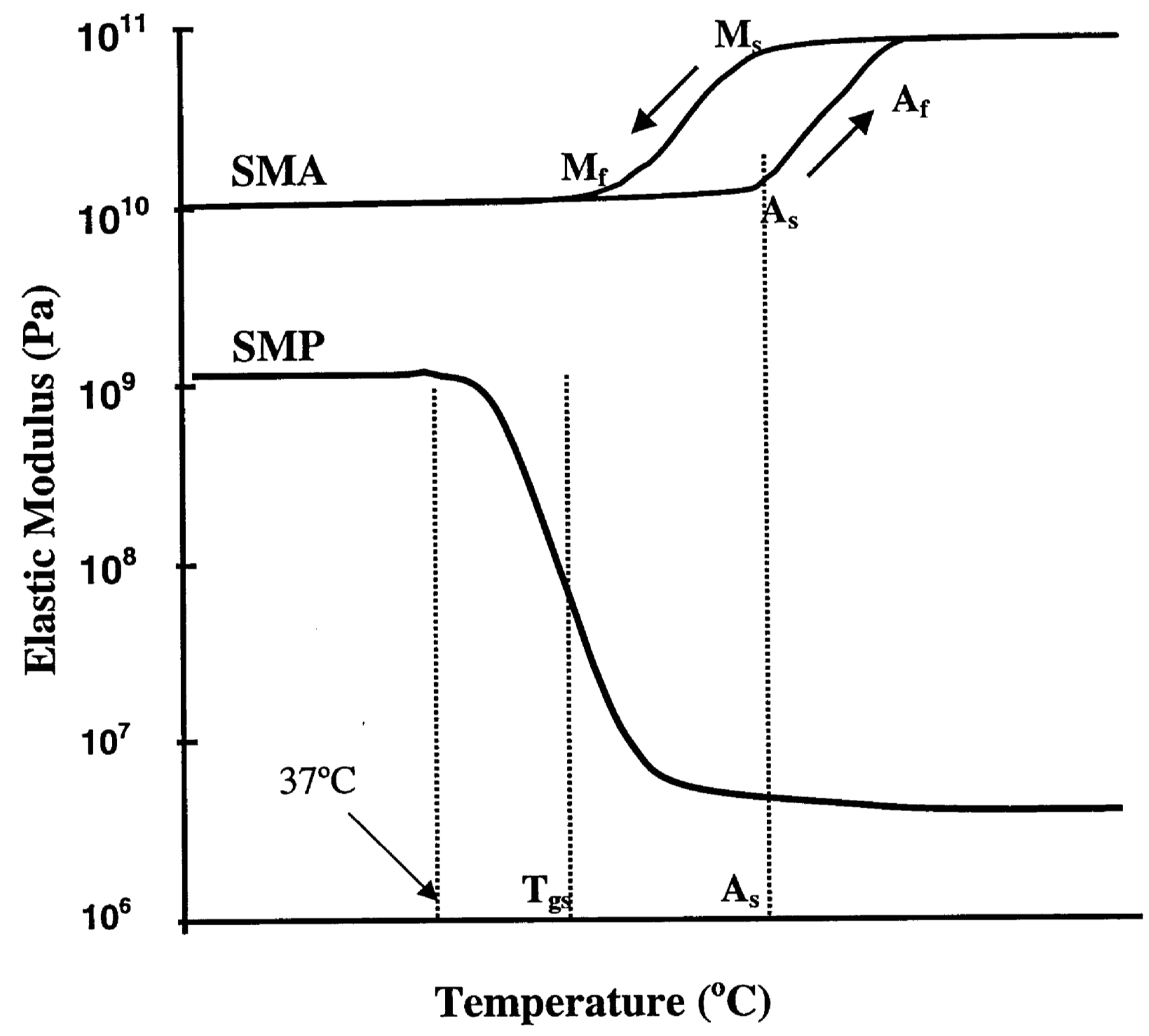

Fig 3 


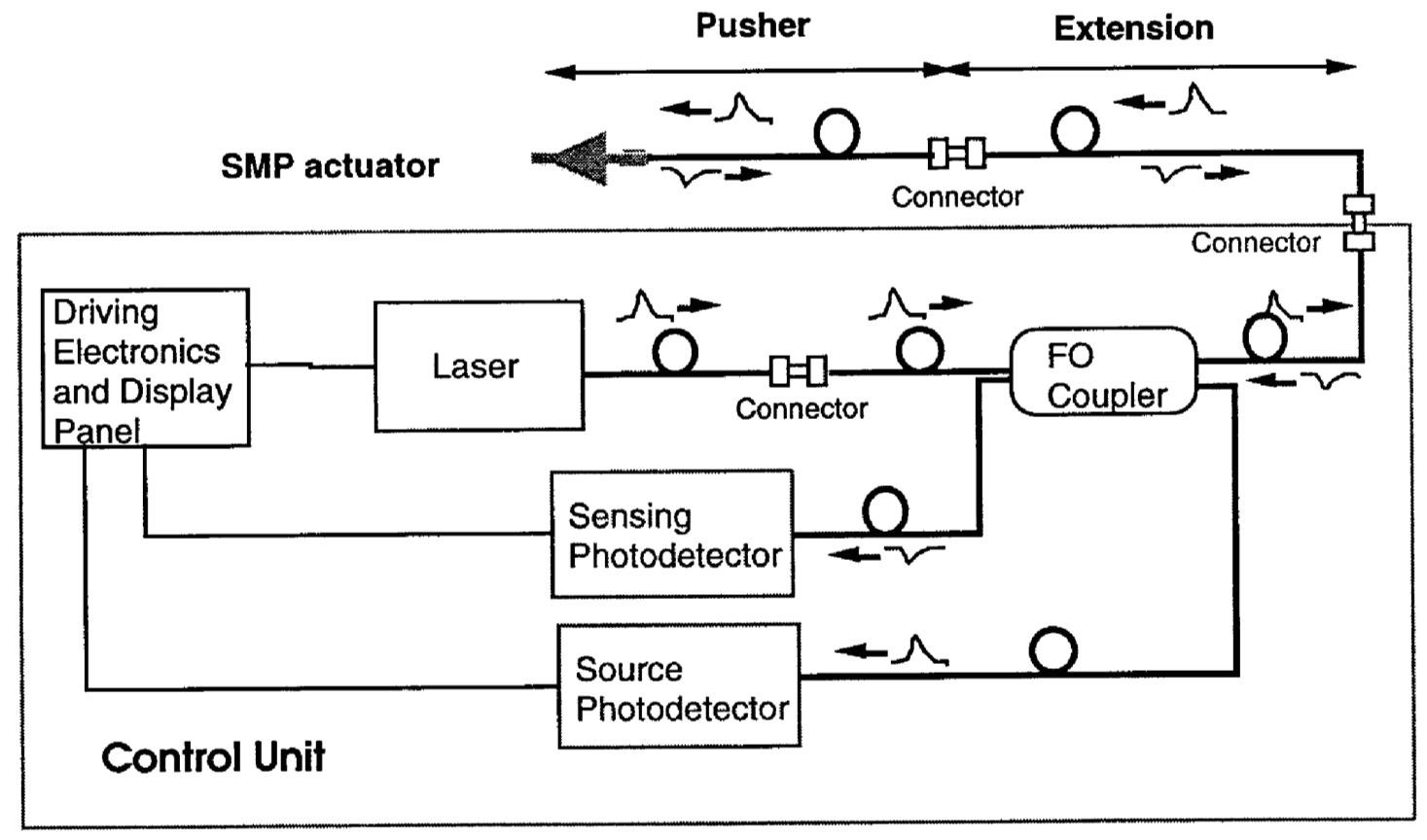

Fig 4 


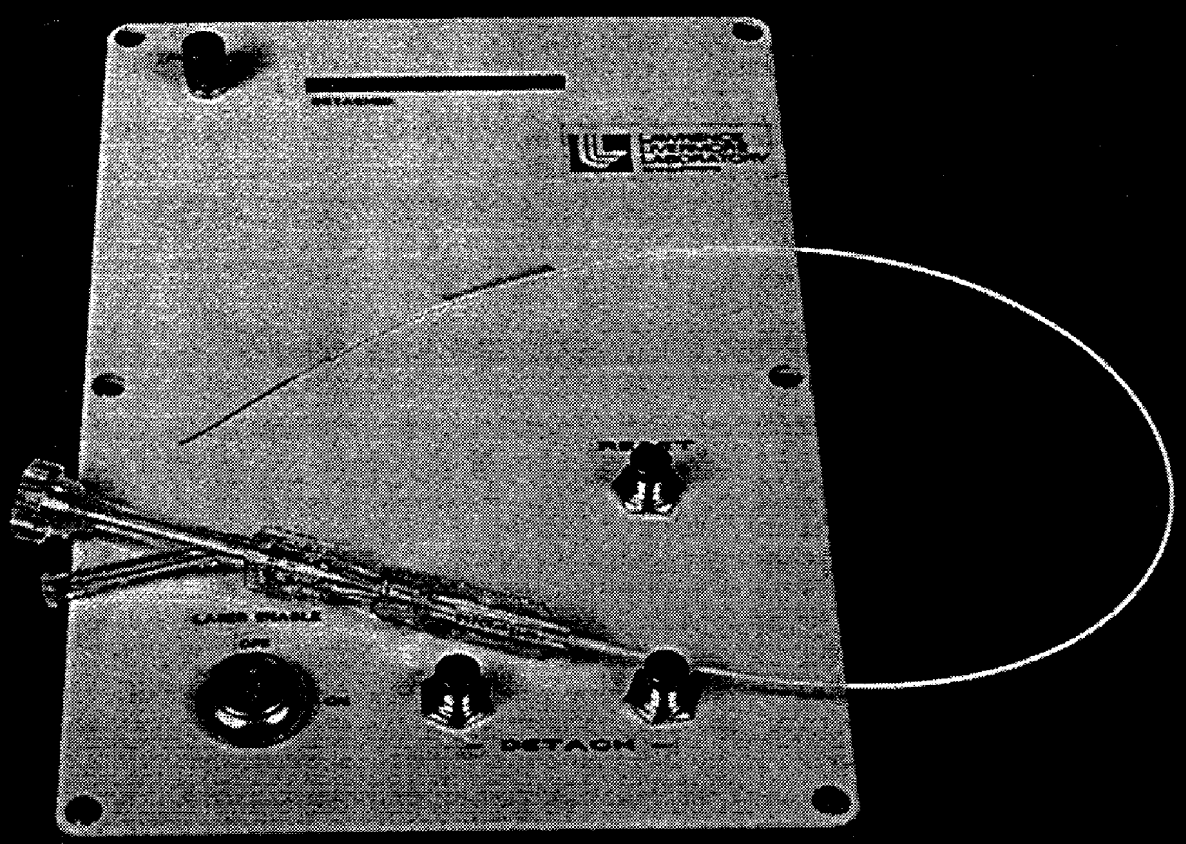

$$
\text { Figs }
$$



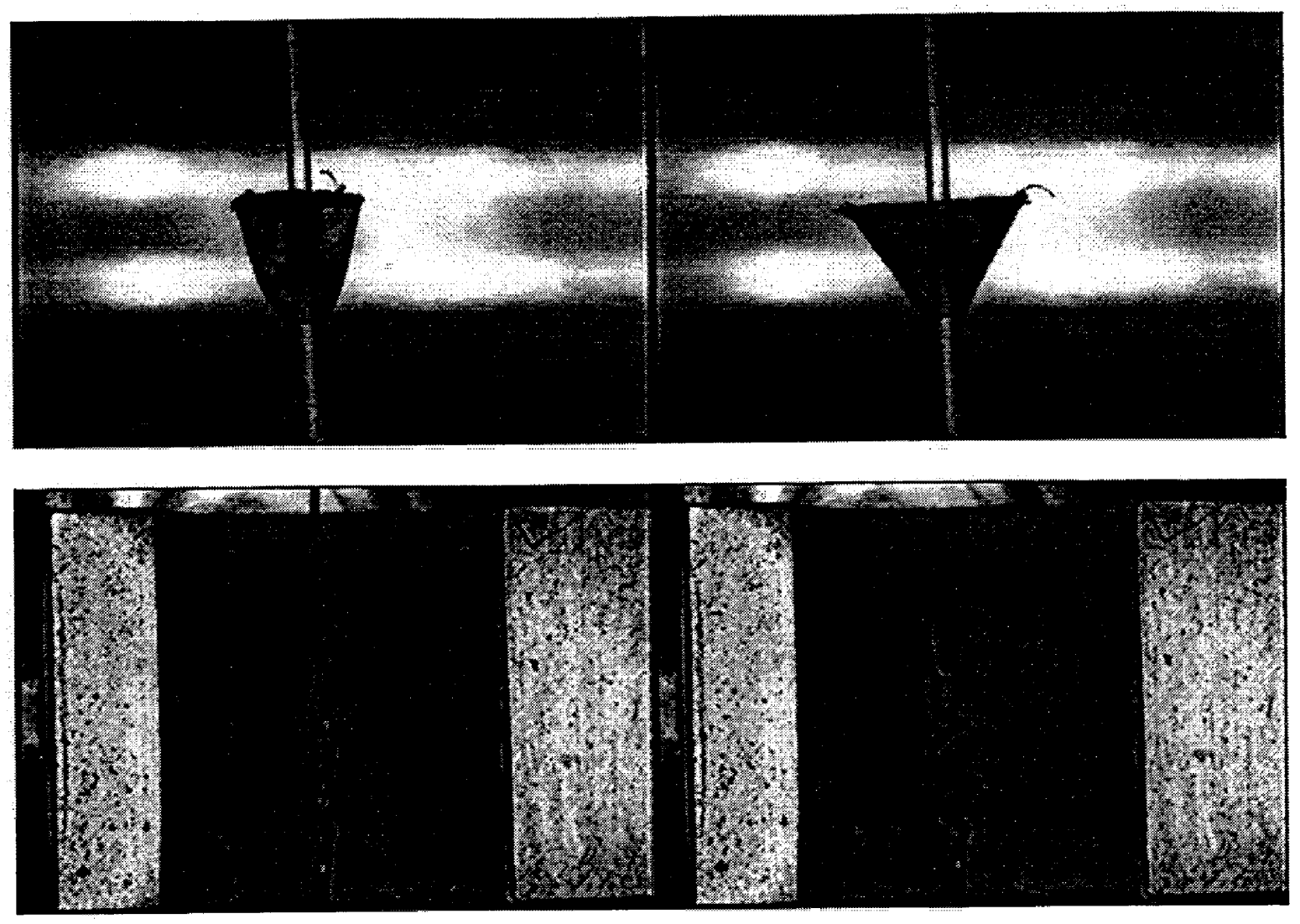

$$
F_{i g} 6
$$




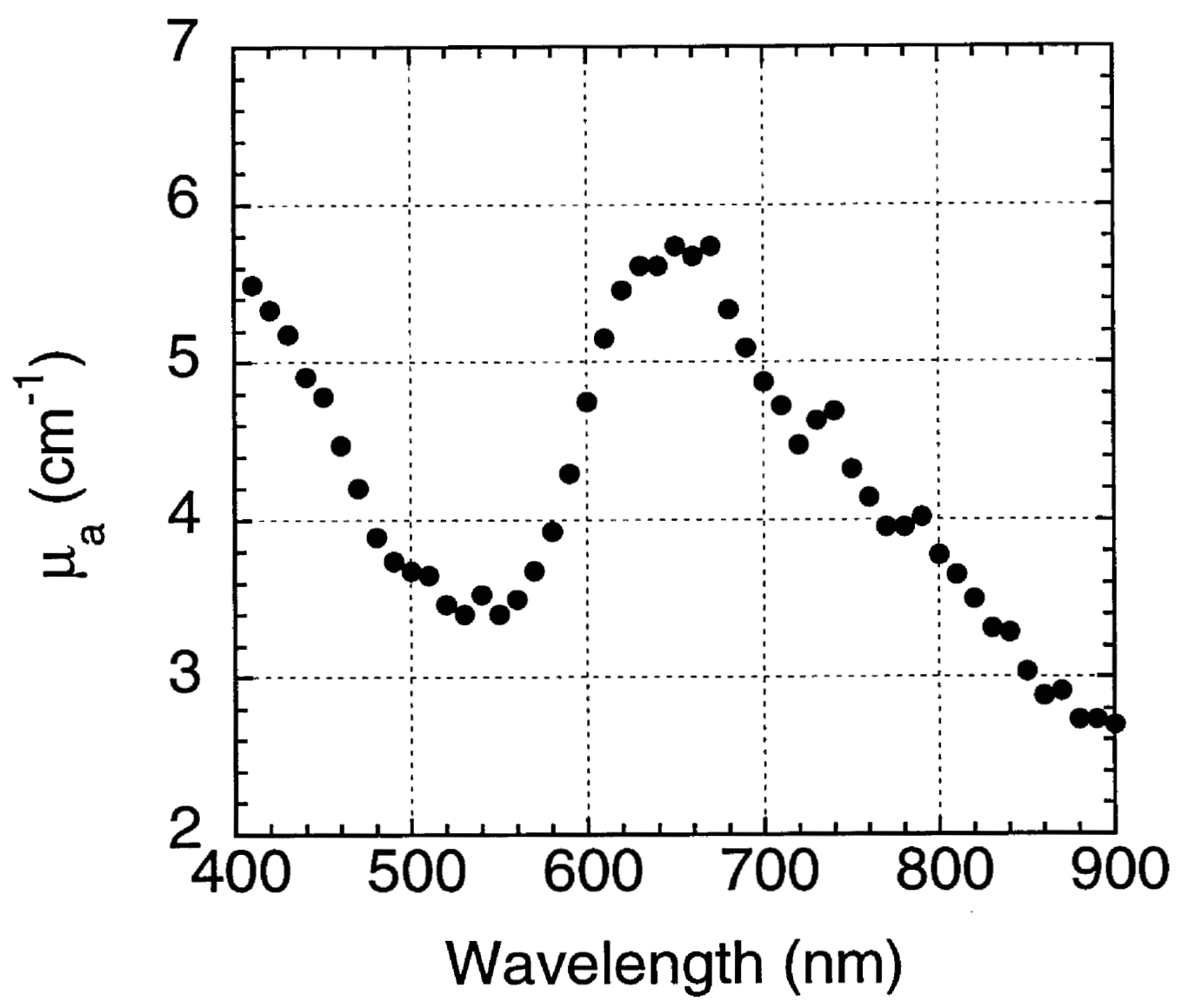

Fis 7 


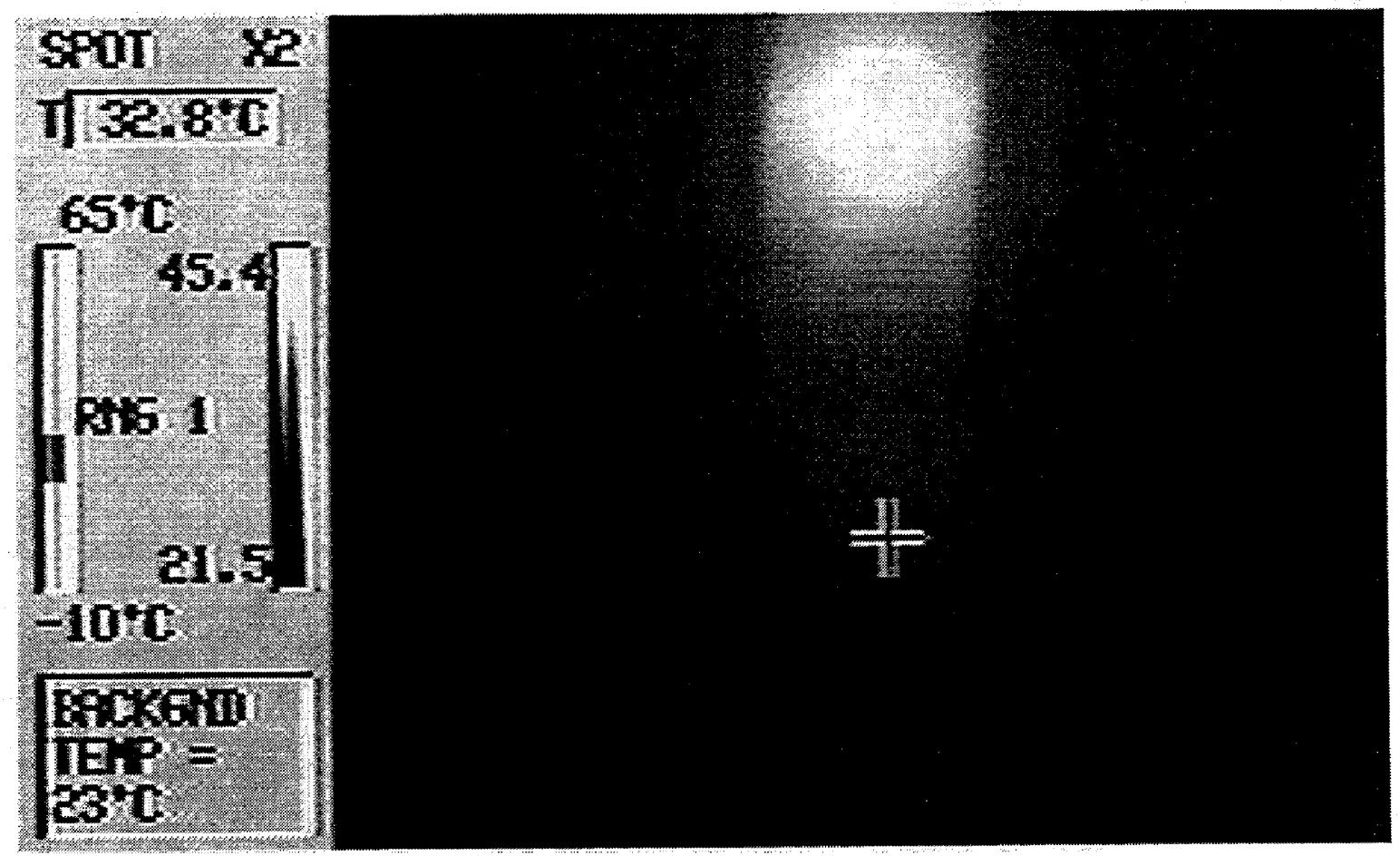

$$
\text { Fig }
$$




\section{D $\quad$ C B $\quad$ A}
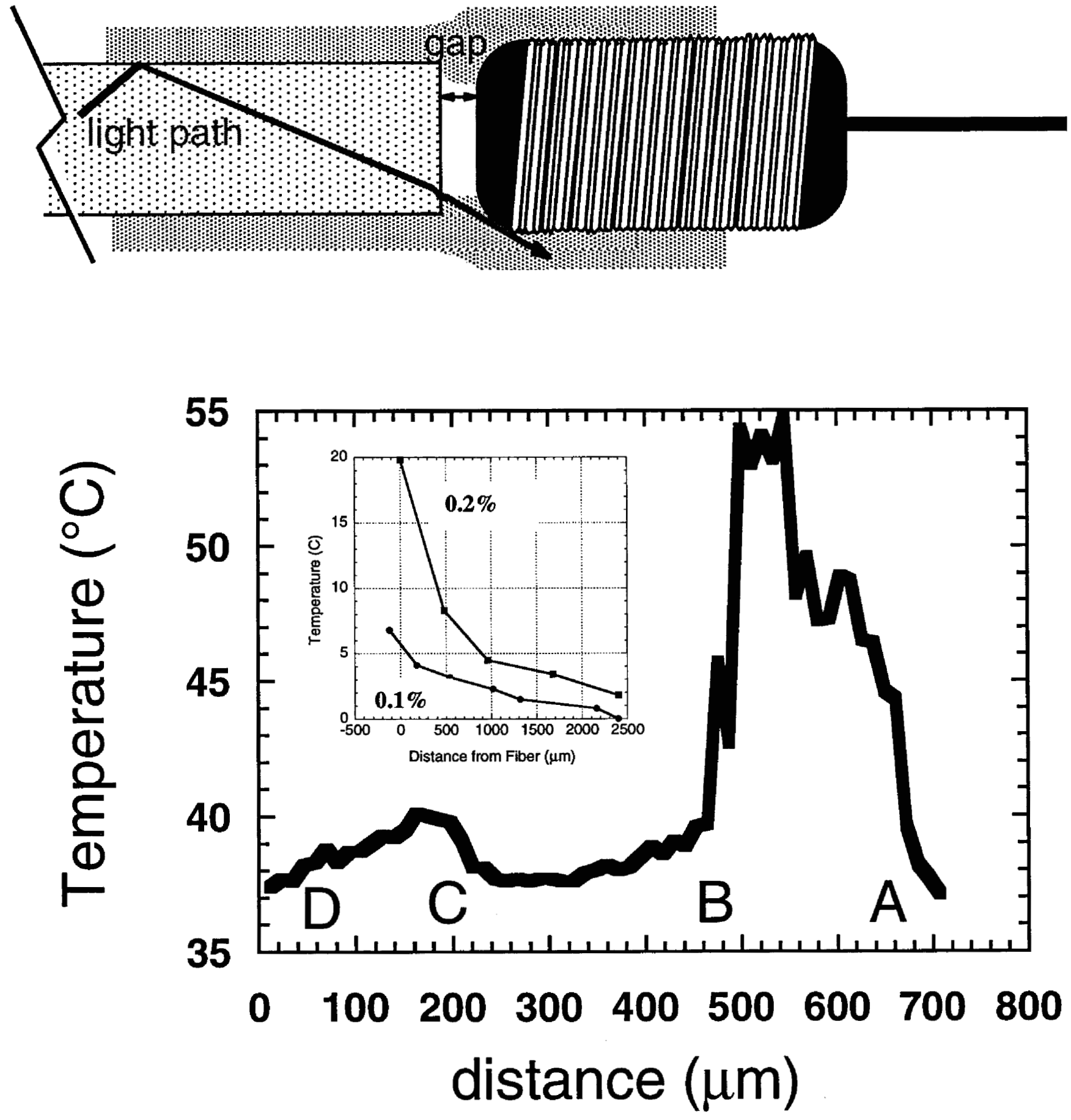

Fis $q$ 

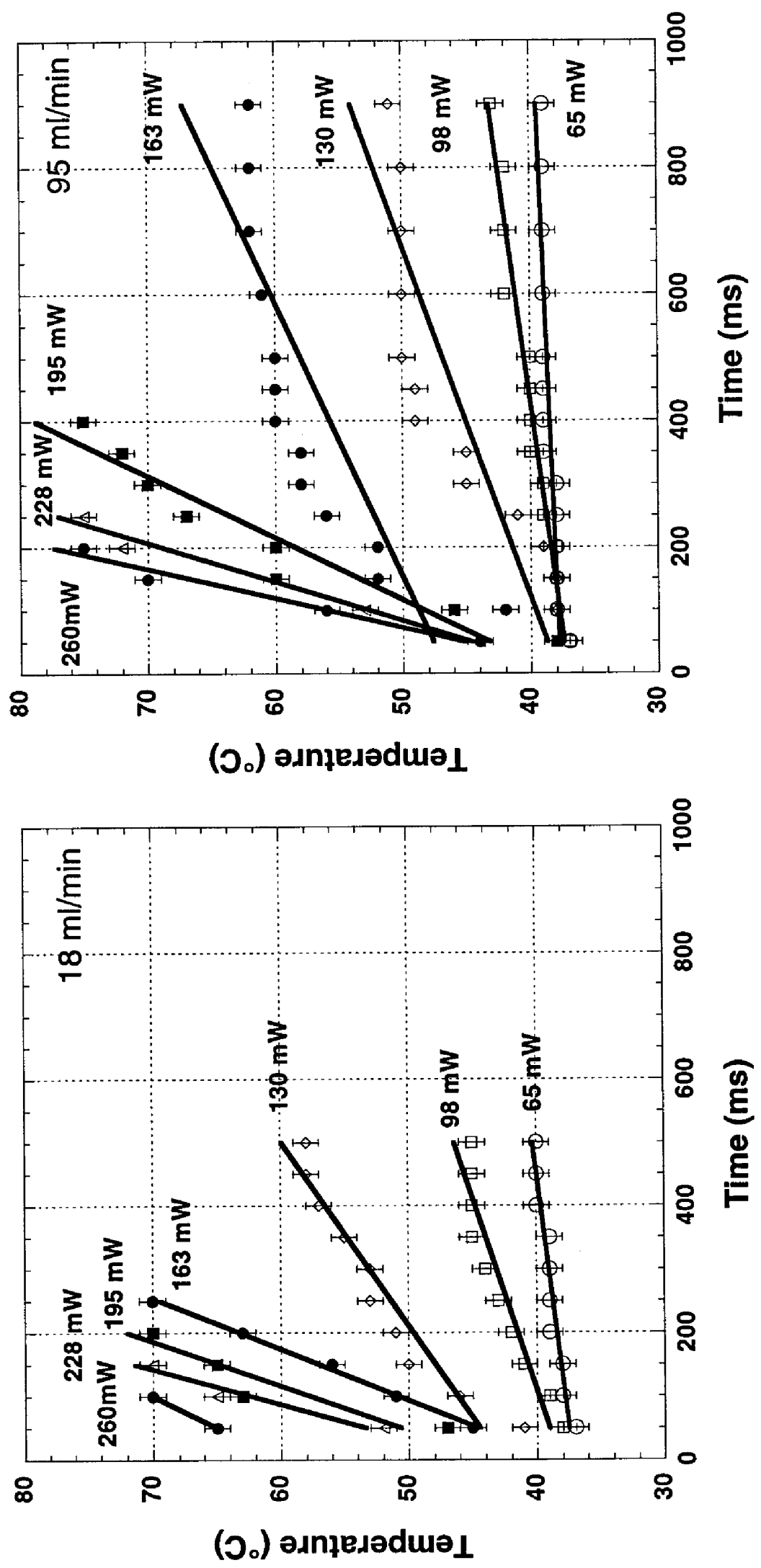